\title{
Dream Paths of Urban Sustainability, Intent to Implementation
}

\author{
Douglas Goudie \\ School of Earth and Environmental Sciences; James Cook University; N. Queensland, Australia.Douglas \\ *Corresponding Author:Goudie@jcu.edu.au
}

Copyright $@ 2014$ Horizon Research Publishing All rights reserved.

\begin{abstract}
This paper provides a generic and useable transition path from sustainability intent to sustainability implementation, using a North Queensland, Australia, case study. The inseparable nature of land use, nodal and transport corridor densities; local needs-meeting and consequent urban travel to and through activity centres provides a coherent intellectual framework, implementation rationale and methodology to achieve greater sustainability. This paper uses urban travel research and a 90-person one-day Paths to sustainability workshop held at James Cook University, Townsville in 2008. Aligned with other like current publications, it is hoped this paper helps urban planning decision-makers head more successfully and deeply into sustainable planning directions within an intellectual framework of applied science.
\end{abstract}

Keywords Urban Sustainability, Planning, Applied Science, Research, Intellectual Framework, Paths, Urban Energy, Ecological Footprint

\section{Introduction}

The goal of the 90-person workshop was to help guide the university to make the campus and intended $\$ 1.3 \mathrm{~b}$ expansion, including about 3,000 more residents, into a vibrant urban hub, a 'living laboratory' and a 'sustainability exemplar'. This paper uses the JCU aspiration to be a world leader in developing urban sustainability to present the 'new way' of planning. The urgency of issues like food-kilometres, global warming and peak oil, along with all planning law and policy demands that we proceed with sustainable urban travel options, from Transit Oriented Development to the development of safe, smooth, direct, continuous and broad paths to and through urban activity centres.

This paper details the coherent intellectual framework which helped inform and grew from the 90-person one day workshop, comparing that with urban sustainability literature and ways to quantify alternative development scenarios to support the uptake of Sustainability Implementation Planning - SIP projects.

By combining locally advanced and integrated thinking on
SIP with emergent quantifiable sustainability index measures and sustainability law and policy, this paper constructs the framework for a new form of science: Sustainability Implementation Science, applicable to SIP. The originality in this paper is to provide a 'Values, Principles and Process' intellectual framework to guide sustainability implementation, then to have measurable and thus comparable alternative strategies to help perhaps fearful middle and senior managers justify moving into the unknowns of sustainability.

The complexity of multi dimension issues and stakeholders, current and future, in implementing urban sustainability means decision-makers need guidance in breaking with the 'old way' and implementing the far more challenging planning 'new way' of inclusive and cohesive planning. Designing for people access with minimised fossil fuel footprint to and through activity centres is a good lead example of how to achieve SIP.

The general methodology of the reported workshop has been used by many - diverse participants, with a weighting of planners and end-users. Most of the outcomes for the already knowledge-based in 'going sustainable' contain no great surprises: nurture local water, nutrients and energy capture, storage and use, build for community and social ease and safety; plan for the long-term with minimised ecological footprint. These are givens. This paper also offers a pathway, a template for any larger organisation which genuinely wants to get beyond well-felt words about sustainability aspirations and to actually engage in the frightening 'whole-of-system' process of creating an unknown future, becoming part of walkable techno-settlements with mainly local needs-meeting.

Finally, this paper is steeped in the Human Geography tradition, unashamedly insisting that, as science is the testable pursuit of accurately explaining changing reality, parts of that reality are that humans have a great capacity to plan; humans have a strong overarching survival urge, and thus, our concern for the future is an element in what is science and valid. Most importantly, the concept of 'impartial science' is structurally erroneous (Walmsley and Lewis 1993). Scientists and others care. Scientists must remain testably reality-based. The relationship between such science-derived knowledge of human prowess and choices of current decision-makers is core to this paper, to the near-term 
viability of our urbanising species. Our species that only started building any permanent structures about 10,000 years back - a blink in time.

\section{Low Fossil Carbon and Environmental Problems, Policies and Laws}

Burning fossil carbon is a core environmental problem confronting the planet. Its use is embedded in unsustainable environmental and socio-economic human behaviours. 'Fossil carbon' has problem subgroups: global warming, peak oil and food provision. We urbanites need to reduce our fossil carbon footprint; to support walking, cycling, transit oriented development and landuse planning which integrates home location with usual household destinations.

The presented decision matrix is based on workshop-supported Values, Principles and Process. This paper details the urban travel and landuse-related outcomes from that one-day workshop. However, to keep transport/urban travel and mobility needs-meeting in its broader sustainability context, a 2013 Vancouver project found that food provision currently contributes $45 \%$ to that city of about 2.2 million people's ecological footprint, with transportation imposing $23 \%$ of the population's total environmental impact (Moore et al 2013).

Section 1 provides a conceptual frame for SIP, the Values principles and processes (VP\&P) model. A research-based value (Figure 1, Goudie 2001, 2002) is that landuse, home location choice and consequent usual travel are three aspects of one issue (Banister 1995). They are inseparable, linked and interrelated. Section 2 describes workshop results surrounding landuse and urban travel, including paths to and through urban activity centres.

Section 3 focuses on sustainability law and policy in Queensland. Section 4, discussion, includes the central planning issue of sustainability: how do we translate the clear law, landuse/planning policy and intent into SIP, linking workshop outputs with current sustainability and transport literature. The conclusion is that a viable urban future combines quantifiable measures of our ecological impact with social indicators to give a measure of sustainability (Amekudzi et al 2009, Sneddon 2000, Turner and Robbins 2008).

'Scenario impact quantification' allows planners and political decision-makers, for the first time, to measurably compare different 'sustainable' scenarios; scenarios which include carbon footprint, cradle-to-grave analysis, embodied and operating energy and water, and indicators of social wellbeing. This paper provides a clear set of process details to help transform institutions and their decision-making groups to break through the fear of the unknown which holds most institutional subgroups from embracing 'the new', threatening, largely untried but increasingly quantifiable paths to SIP.

Two final context setting Figures are offered. Figure 1 emerged directly from the workshop. It strives to illustrate that there is ultimately a gross disconnect between 'knowledge-holders' - researchers and evidence-based material - with middle to upper level decision-makers, in business, government and nearly all institutions. Evidence the clear gap between Sustainability law and policy across the planet and actual practice. There is a wealth of knowledge available on SIP, but few comprehensive 'all of system' examples, despite global intent being clarified since 1987 (Bruntland). My view is that the lack of 'traction' between sustainability knowledge and upper-level decision makers is the root problem the biosphere and our future wellbeing face.

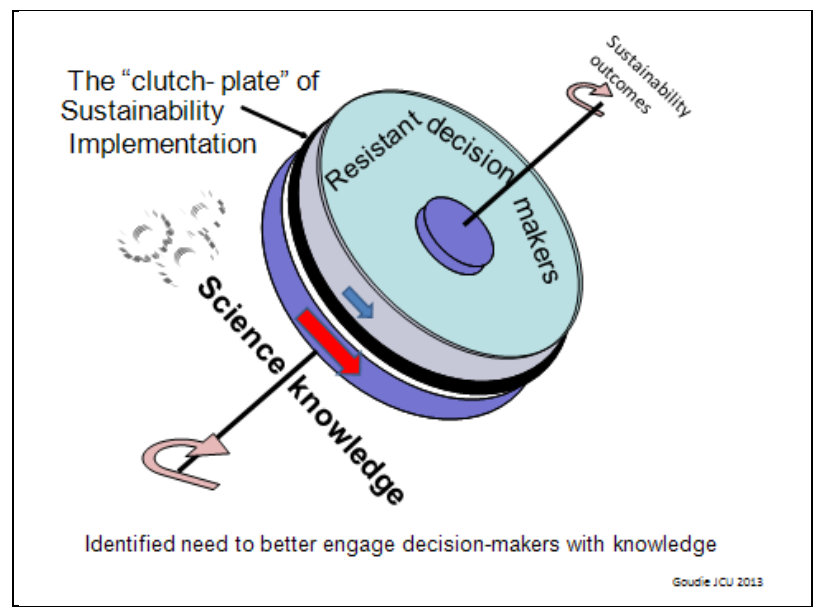

Figure 1. Main impediment to sustainability implementation

Figure 2 'Curve 1', I argue, is all we need to know about human prowess in time and space. No other species has made copper wire, for instance. Since the last ice age, our increasing settlement and achievements are astounding.

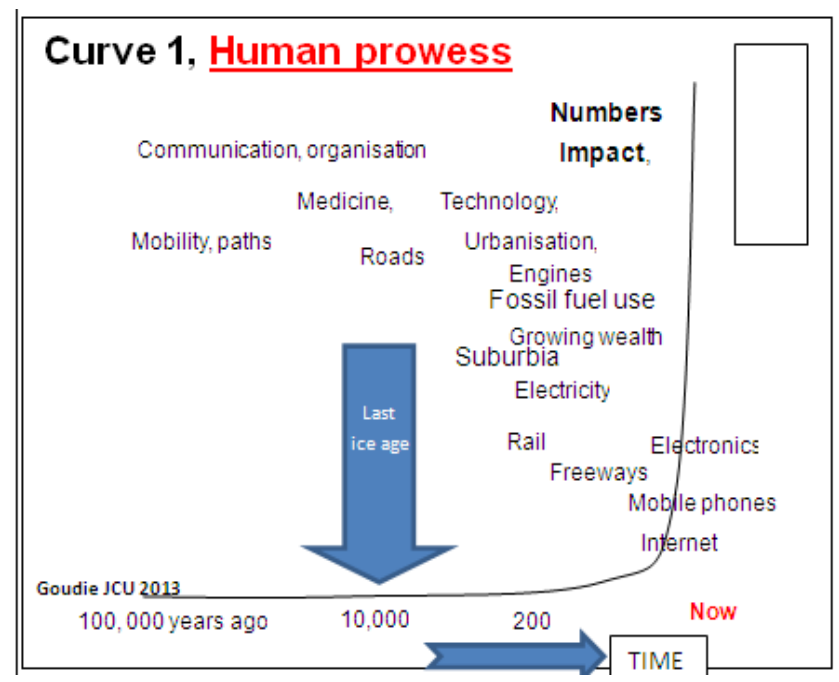

Figure 2. Human prowess since the last ice age

The focus of this paper remains firmly on landuse and more sustainable urban travel, while emphasising the broad and integrated social, economic, environmental and cultural issues to steer societies toward urban sustainability.

Step 2 in the Paths to sustainability process (Fig. 3) is 
being developed by JCU Townsville from July 2009, when a 'high level' focus group on residential issues agreed that aspects of sustainability - social, environmental, economic and cultural, could be bundled together and badged as urban sustainability. SIP's premier value is that planning must be place-based and end-user driven. This means Discovery Rise (DR); the intended \$1.3b makeover to a University Village in Townsville can credibly use the unifying label of urban sustainability. That requires nine interlocking elements (Figure 4) by combining: a community with economic drivers in education, research and development; so all planning, design and behaviour enhances profitable university-related enterprises.

Using DR as a lead example, urban sustainability also includes ESD in the tropics. DR must be socially sustainable through community engagement, integrated planning, affordable living, equity of access and diversity. Finally, urban sustainability at DR must foster cultural identity and diversity of backgrounds and ages, protecting and enhancing cultural roots and growth through civic activity. Urban sustainability will be achieved through an emerging Science: Sustainability Implementation Science (SIS, Goudie 2013).

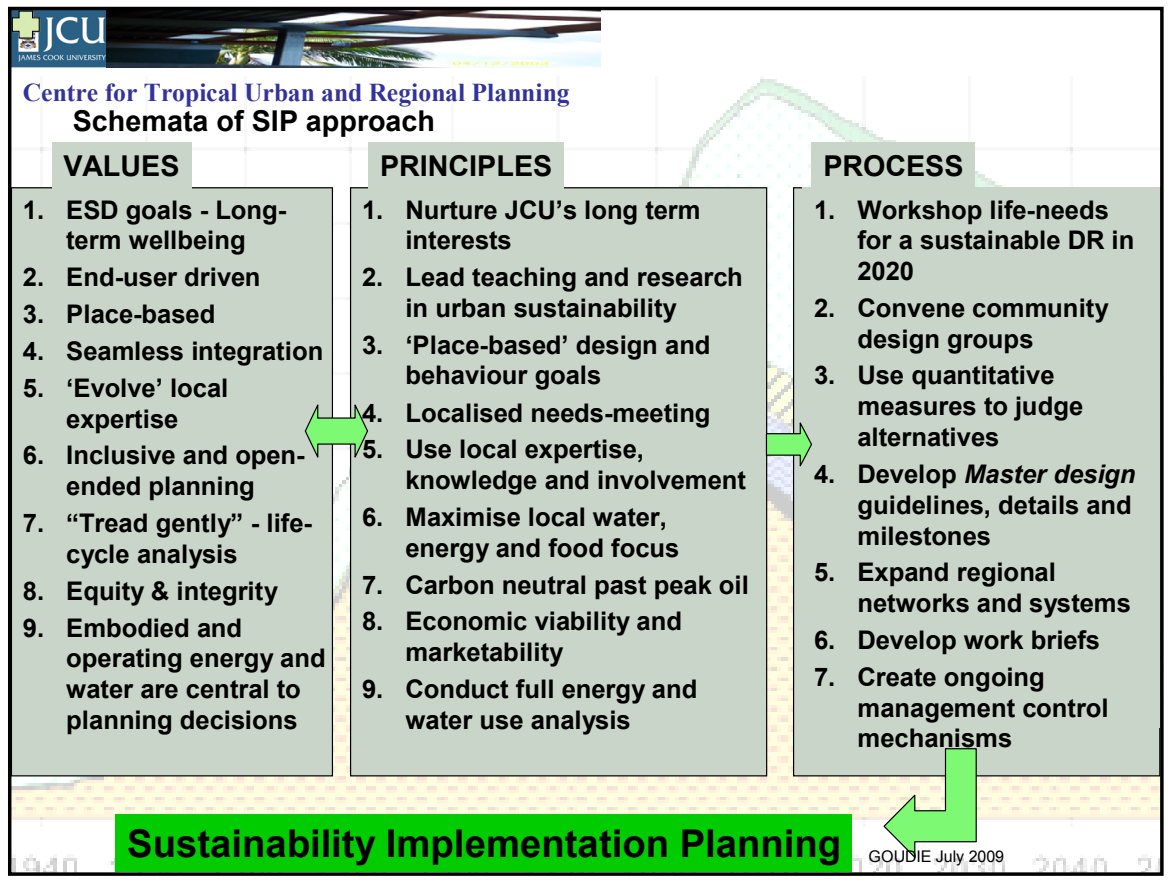

Figure 3. Planning Values, Principles and Processes

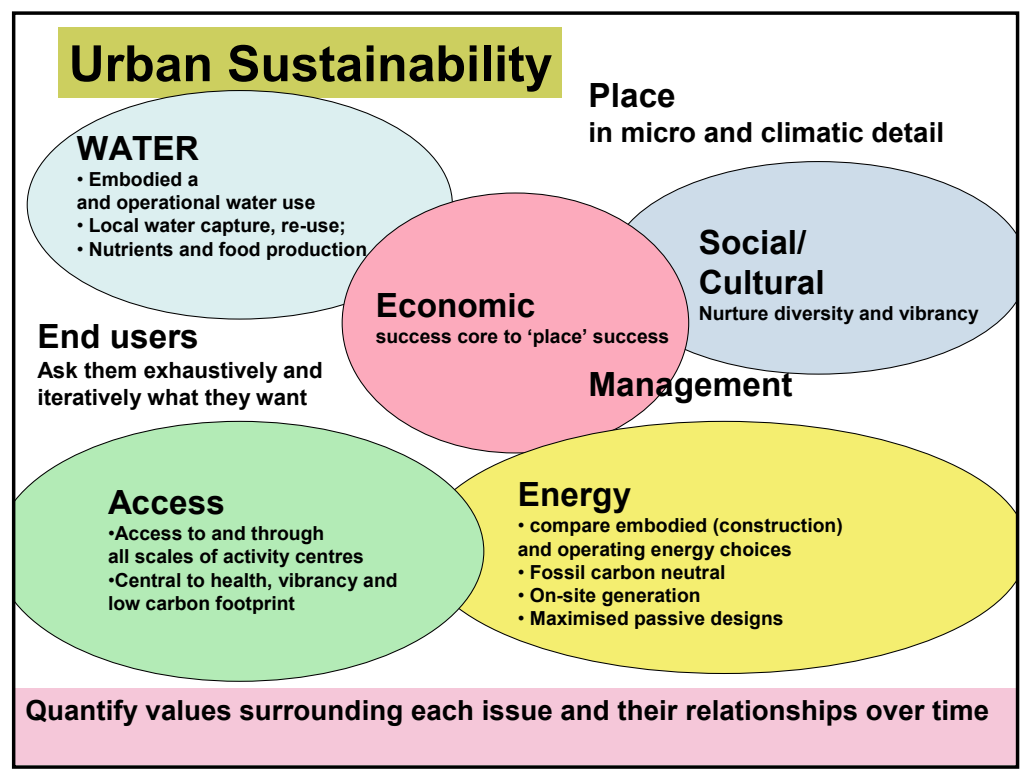

Figure 4. Sustainability implementation science and key planning issues 


\section{Conceptual Framework of SIP}

This section provides a conceptual frame for SIP. Based on the belief that humans have a strong survival urge and a clear ability to plan ahead and form large cohesive groups (Stern et al 1995), the following values, principles and processes are a roadmap from ecologically sustainability intent to sustainable planning action.

A key problem in achieving a holistic approach to SIS is that the last 200 years have so successfully developed by reductionist specialisation (Sneddon 2000, Curve 1). From education to engineering, from politics to planning, the specialist drills into specific problems and becomes narrowly expert. Because of this 'silo' structure, solving multidisciplinary problems like achieving urban sustainability is daunting and without much precedent. The challenge now to work across society in time and space (Barnes 2004) is highlit by the difficulties in getting even one section of one organisation cohesively working with another section (Amekudzi et al 2009). This is the central challenge we face and must overcome.

\subsection{Sustainability Implementation Science - SIS}

Sustainability implementation science can be conceptually viewed as a Venn diagram, where SIS is the outer boundary. Within SIS there are permeable clusters of issues. Broadly the grouped issues are fossil carbon, environmental, social and cultural, planning, management, law and policy. There is an increasingly important addition to these clusters, a reproducible and 'green/sustainable' way to quantify alternative planning scenario decisions in sustainability terms.

Embodied and operating energy and water use are clear and quantifiable central issues in SIP (Figure 4, Koo and Ariaratnam 2008). Decision-makers, planners and their employers can now quantify and compare all the relevant (and external) project costs over time. End users are placed centrally in the SIP methodology for any planning decision. Quantification is the emerging lever to properly translate strong SIP intent into SIP action. In Figure 4, 'Place', Management and end-users are depicted as ubiquitous. All subsets should, ideally, overlay each other, and be open-ended to 'the outside world'.

James Cook University intends using 60 ha of land not directly needed for academic use to leverage a $\$ 1.3$ billion makeover to become Discovery Rise, a sustainability exemplar. JCU's plan is to 'engage with industry and government.' 'JCU is a site and catalyst for innovation and understanding... to be a global leader in environmentally sustainable infrastructure development (and) operation in the Tropics" (JCU 2008). "It will be an integrated community of living and learning that will set a new benchmark in sustainability, and will enhance JCU as a leading tropical university" (JCU 2013).

\section{Method}

\subsection{Paths to sustainability workshop}

A place-based and end-user driven 90-person workshop was conceived by JCU planners and the Centre for Excellence in Tropical Design (http://tropicaldesign.org/) to progress the genuine aspiration for JCU to foster future viability of the Townsville campus. The process was chaired by the author. The goal was to map the elements and paths needed to get the best long-term use of existing land and regional knowledge resources. A working group of university, state and local government planners developed the workshop over three months. It was oversubscribed, with diverse attendees.

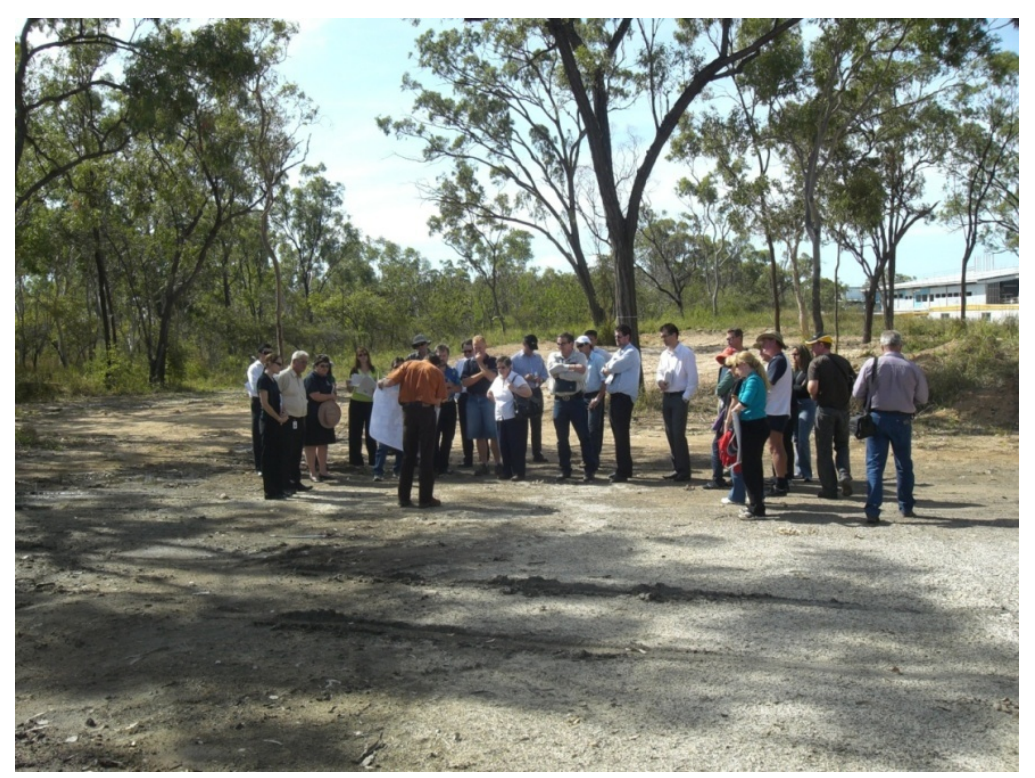

Figure 5. Some paticipants prior to the workshop, making sure of the actual site 
The workshop went through a series of 'think and discuss' group exercises to develop aspirational goals, through to what is essential for this site and end-users to achieve sustainability. As it related to urban travel, connectivity between nodes and a focus on paths for pedestrians, cyclists; wheelchair and pram users was developed; a vision of what would provide a sustainable access mix to and through the campus. The group of 90 was also asked to define what future focus groups they wanted to be in. Forty-three attendees volunteered 103 focus group topics to help steer the broad, University-focused urban development into becoming a sustainability exemplar, a living laboratory.

Figure 5 shows some participants, one week prior to the workshop, having a detailed site inspection, embracing part of the philosophy, the values of SIP for all planning to be specifically place-based in all aspects. Some participants were academics, some were theatre and creative people, some were planners or students, all subscribing to the principle that all SIP should be end-user driven (see Figure 3).

\subsection{Broader Inclusions}

The workshop helped develop and add to the VP\&P methodology. Needing to integrate with surrounding activity centres forming a larger destination node, the working group invited decision-makers from the nearby army base (the largest in Australia); the adjacent regional hospital and nearby major shopping complexes. They all attended the workshop.

The Townsville mayor attended the workshop and prior site inspection (Figure 5), along with many council and planning, developer and JCU student and staff representatives. The Vice Chancellor attended and, like the Mayor, responded to the group during the workshop summation. There was broad involvement and support from representative end-users and encompassing decision-makers.

\section{Results}

Workshop outcomes are given from 10 groups, focused on more paths, less cars, and housing near usual destinations or attractive transit stops. The following results follow the processes of the day, starting with Aspirational statements about what a sustainable campus and urban settlement on the $J C U$ site will need to be successful.

\subsection{Aspirations}

"Community integration and social fabric, vibrancy, with enjoyable living. Bring the wider Townsville community to our campus, attracting people to our engineering or water solutions. Zero carbon footprint. Connect the university via an innovative transport system through all nodes. All town needs; reliable public transport - perhaps light rail. Attractive unique facilities. Connected, legible and accessible. People walking, cycling. Connected paths, fewer roads. Reticulated, recycled water. Community food gardens. Carbon neutral renewables. Energy monitoring. Direct/easy access. Healthy people movement; Facilitate amenity. Suburbs living together. Strong, collaborative linkages and networks."

\subsection{Ideally}

"ACCESS: Public transport - reliable. Light rail. Densification. Clean transport within the university. Integrated bicycle/pedestrian traffic. Hard engineered spaces to provide visible shaded movement corridors that link nodes of mixed use. Bicycle pooling. Shady. Medium density housing. Choice. High rise. WIDER LINKS: Accessibility to the university - transport on macro level. Connecting JCU with community via: an innovative transport system - fast, efficient, integrated connecting critical nodes in the city. Light rail linkages (city, beaches). Dialogue with hospital, defense and community. E.g. most desired services. Synergies."

\subsection{Necessary}

"Recognise DR as a central transport node, integrated with the city transport system. Have weather-protected paths. User-pay car parking to reduce demand. Pay to park and to transit.

Committed plan for local area code - include each precinct, with specific plans and codes to control developments - height, density, carbon foot-printing, open space, car parking, building specifics like minimum overall sustainability elements which can be allowed, specific transport links between DR and other Townsville centres. For the town centre, commitment to community service needs, and ensuring links to surroundings.

Design from first principles. Transport to be low energy, at the human scale, convenient and easy to use.

Community - conscious of safety and security in design. Passive and active. Provision of regionally significant infrastructure, activities and attractions. Bring users together to overlap. Blending academic, residential, commercial and recreational purposes. Energy and resources - the development to have grid-fed renewable energy, with zero carbon footprint target."

We are going into a new place, a technological city or town; a village that is sustainable, and the planet hasn't done it before.

Workshop groups said: "Residential accommodation will be along corridors and nodes of medium and high density dwellings. Transit centres within the university (Transit Oriented Design) also appropriate for users coming to and leaving university (e.g. coming to an evening event).Car free environment: bike and pedestrian networks internal and external. Maximum public transport. Electric vehicles on site. Public car park node. Minimisation of roads/car park footprint. Cycle access routes weather protected. Enough 
space for secured bike spaces at all residences and campus buildings. User pays parking. Abolish the use of fossil fuel transport within campus. Climate sensitive movement networks. Internal transport and pedestrian design commitment from all. Transportation within the site will be low energy, human scale and convenient.

Encourage diverse mix of people in as many areas as possible. Provision of pathways to encourage pedestrian and cyclist migration between precincts. Vegetated. Natural shaded and cooled water features to reduce air temperature. Design shall be on a human scale (not vehicle scale)."

Table 1 details what participants thought most important for sustainability implementation. Their input is grouped into six broad areas to help focus on the structures needed to achieve the integrated sustainability goals.

\subsection{Suggested Inclusion in Ongoing Focus Groups}

\section{Half the participants volunteered for self-defined ongoing}

focus groups. As they relate to landuse/access: "Bicycle use. Alternative transport design. Minimise carbon footprint. Sustainability and energy solutions. Renewable energy and energy efficiency. Carbon offsets. Water/nutrients. Food/nutrients. Food production. Composting, community gardens. Links to adjacent and further cluster partners."

Some reference to the water/nutrient/food production has been left in this paper because it is a key decision-maker in broad sustainable urban landuse and can be quantified as part of the ecological and social indices (Gosh et al 2009, Harris 2009, Yakubov 2009).

Figure 6 shows the five distinct zones intended for the future of the broader JCU site. It has drawn from the workshop results in many aspects, focused on the core business of the university - teaching and research in the tropics, while paying much attention to social and cultural integrity and cohesion for the proposed 3000 new residents.

Table 1. Necessary statutory planning guidelines 1 - Actions; what can be

\begin{tabular}{|c|c|c|}
\hline Group & Generic & Full Sustainability Implementation Planning \\
\hline $\begin{array}{l}\text { 1. JCU Core } \\
\text { Business: teaching } \\
\text { and research; } \\
\text { economic viability } \\
\text { and 'life-cycle' } \\
\text { modelling; } \\
\text { land-tenures; } \\
\text { sustainability } \\
\text { project governance. }\end{array}$ & 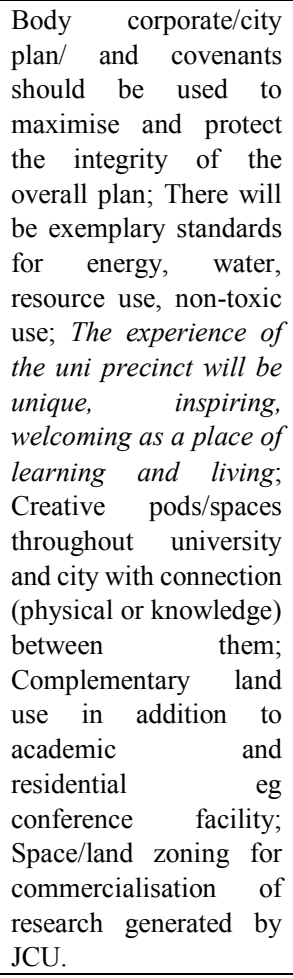 & $\begin{array}{l}\text { Development control rests with the university community. Note ongoing management future } \\
\text { flexibility needs to be able to be managed by the form of tenure chosen. } \\
\text { Must set a level of investment. The model should be outcome driven and have both long-term and } \\
\text { short-term commercial gains for JCU; University creates Body[s] Corporate for life of } \\
\text { development to regulate quality of amenity and lifestyle; The commercial partnerships for } \\
\text { developers will be innovative to achieve both commercial viability/profitability and exemplary } \\
\text { quadruple bottom line sustainability outcomes for the university and uni community. } \\
\text { JCU needs a tenancy strategy to encourage the right tenant mix first up. Once proof of value in } \\
\text { area - lease conditions can be changed.; S97A Land Act - registration of covenants on title to } \\
\text { protect areas; Control of the individual and overall built environment and the use thereof to } \\
\text { maintain the master plan - "mechanism to preserve intent"; Control of the individual and overall } \\
\text { built environment and the use thereof to maintain the master plan - "mechanism to preserve } \\
\text { intent". } \\
\text { Realistic business plan to ensure the identity of the vision is preserved in the - commercial; } \\
\text { social; environmental considerations of the proposed community; Time sequenced commitment } \\
\text { to implement all guidelines incorporating research and implementation. } \\
\text { Sale of land must ensure that other desired outcomes are concurrently met; Specific local area } \\
\text { code (committed plan) including: various precincts - town central common/business; gateway; } \\
\text { student residential (uni owned); multi-res (multiple ownership); traditional residences. Specific } \\
\text { intents and outcomes for each precinct. Specific development codes to control built design; } \\
\text { landscaping; density/height/lot sizes/site ratio; car parking. } \\
\text { Learning environment: precincts must encompass and support the core business of JCU i.e. } \\
\text { Teaching, research and empowering exchange within the wider community eg maintaining } \\
\text { natural vegetation and waterways for student studies, research as well as teaching; Must } \\
\text { encourage flexi-time approach to address peak demand of services (safety, individual } \\
\text { opportunities). }\end{array}$ \\
\hline $\begin{array}{l}\text { 2. Housing extra } \\
1000 \mathrm{~s} \text { Locations, } \\
\text { form and } \\
\text { sequencing }\end{array}$ & $\begin{array}{l}\text { Promote best practice } \\
\text { building initiatives. }\end{array}$ & $\begin{array}{l}\text { Promote housing affordability - keep student accommodation costs down but high quality; } \\
\text { provide diverse accommodation pricing (benchmark against current pricing); No detached } \\
\text { dwellings; Housing: embedded energy targets to be set and met; Residential accommodation will } \\
\text { be along corridors and nodes of medium and high density dwellings; Solar collection on all } \\
\text { dwellings. }\end{array}$ \\
\hline $\begin{array}{l}\text { 3. Vibrant town } \\
\text { centre: social, } \\
\text { vibrant, cultural, } \\
\text { arts, performance, } \\
\text { foods, major } \\
\text { regional attractants. }\end{array}$ & $\begin{array}{l}\text { Social; } \\
\text { retail/commercial; } \\
\text { arts/entertainment; } \\
\text { recreation. }\end{array}$ & $\begin{array}{l}\text { Transit centres within the uni also appropriate for users coming in and leaving uni (e.g. coming to } \\
\text { an evening event); Specific timing/stages for central hub services - university commitments to } \\
\text { community service provisions; Community: provision of regionally significant infrastructure - } \\
\text { sporting facilities (state/national/international); Community centre; Draw on and incorporate - } \\
\text { Indigenous knowledge/culture; curriculum; planning; culture; Density must be determined, mix } \\
\text { of social and cultural; Land tenure options must be determined eg private ownership; leasehold; } \\
\text { combination of both; sources of funding, benefit to JCU; covenants. }\end{array}$ \\
\hline Infrastructure: & Resource & Fixed policy on hard engineered solutions. Will lock in design parameters relating to renewable \\
\hline
\end{tabular}

1 From the 'social learning' process used and facilitated by Prof. Valerie Brown, Table 1 shows the emergent outcomes of the workshop. 


\begin{tabular}{|c|c|c|}
\hline $\begin{array}{l}\text { water/food/ } \\
\text { nutrient; daily } \\
\text { access; energy } \\
\text { provision and use; } \\
\text { outside links and } \\
\text { access }\end{array}$ & 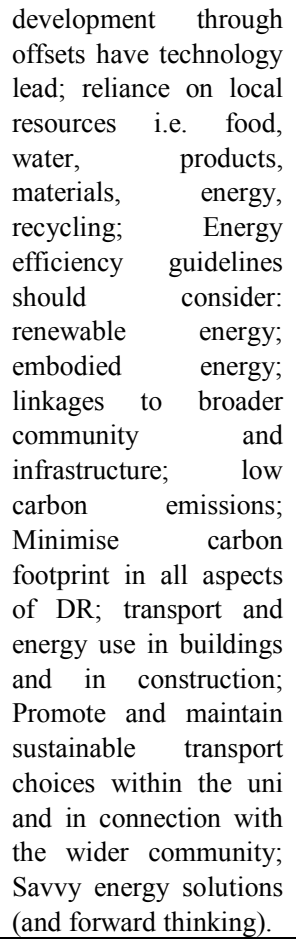 & $\begin{array}{l}\text { energy and waste reduction. } \\
\text { ACCESS } \\
\text { Car free environment: bike and ped networks internal and external; max public transport; electric } \\
\text { vehicles on site; public car park node; minimisation of roads/car park footprint; Cycle access } \\
\text { routes weather protected; enough space for secured bike spaces at all residences and campus } \\
\text { buildings; User pay parking; Abolish the use of fossil fuel transport within campus; Climate } \\
\text { sensitive movement networks; Internal transport and pedestrian design - commitment from all; } \\
\text { Transportation within the site will be low energy, human scale and convenient. } \\
\text { ENERGY } \\
\text { Use of "highly efficient" machines; Need to ensure carbon neutral in development and use } \\
\text { phases; All buildings must incorporate renewable energy generation: maximise usage subject to } \\
\text { technology and economics; aim to export energy; minimise embedded energy; Provision of grid } \\
\text { fed clean energy; Target of zero carbon footprint (through development also); covering entire } \\
\text { master plan; Implement micro and macro energy use monitoring systems eg smart meters. } \\
\text { Accountability of access use. Community awareness portal located central to campus. } \\
\text { WATER/FOOD } \\
\text { Water Aim - no net change in hydrologic characteristics in adjacent earthworks; Water Quality - } \\
\text { Urban design: must embrace all new water sensitive urban design guidelines and principles; } \\
\text { Manage on site - grey water, utilise and recycle; Investigate native species and revegetation and } \\
\text { provide resources for local food production. } \\
\text { WIDER LINKS } \\
\text { Topicality as well as Research and Innovation - linked directly to industry and community; focus } \\
\text { on sustainability; Must be proactively responsive to external ideas, opportunities and drivers; be } \\
\text { that in respect of curriculum, service provisions, business, research, social and cultural } \\
\text { aspirations; Learning available within and outside via communications technology. }\end{array}$ \\
\hline $\begin{array}{l}5 . \quad \text { Cohesion: } \\
\text { people and } \\
\text { activities } \\
\text { diverse Inviting, } \\
\text { integrated, and } \\
\text { overall integrity }\end{array}$ & $\begin{array}{l}\text { Widest mix of diverse } \\
\text { uses that are } \\
\text { complementary to the } \\
\text { uni that will ensure the } \\
\text { long term economic } \\
\text { future of the uni; } \\
\text { Maintain community } \\
\text { interaction. }\end{array}$ & $\begin{array}{l}\text { Whatever development occurs should promote, complement and enhance university integrity; } \\
\text { Integration and connectivity: bring uses together to overlap where possible, being mindful of } \\
\text { conflicts; academic, residential, commercial, community recreation; Encourage diverse mix of } \\
\text { people in as many areas as possible; Provision of pathways to encourage pedestrian and cyclist } \\
\text { migration between precincts; vegetated; natural shaded and cooled water feature to reduce air } \\
\text { temp; Design shall be on a human scale (not vehicle scale); Other facilities for all residents: } \\
\text { creative/leisure/sport; Ensure building codes encompass the ability to facilitate technical change. } \\
\text { Maintain and enhance the biodiversity of the precincts to minimise detrimental impacts overall on } \\
\text { the natural environment; maintain fauna corridors and waterways and significant natural } \\
\text { vegetation; "university town" - mixed uses and activities - integrated learning, research, work, } \\
\text { commerce, community facilities, recreation, agriculture/food production; Visual amenity of } \\
\text { landscape: maintain scenic rim; maintain endemic vegetation; maintain and enhance natural creek } \\
\text { lines; Combine walking trails with environmental features; Must have design that responds to the } \\
\text { local and regional, cultural, climactic environment. }\end{array}$ \\
\hline $\begin{array}{l}6 . \quad \text { Cohesion: } \\
\text { Landscape and } \\
\text { buildings }\end{array}$ & $\begin{array}{l}\text { Must have its own } \\
\text { unique identity and } \\
\text { differentiation from } \\
\text { other residential/ mixed } \\
\text { use communities that } \\
\text { catalyses desirability }\end{array}$ & $\begin{array}{l}\text { Must have open space as formative/organisational framework, leading to high quality built } \\
\text { environment and landscapes celebrating sense of place; Safety/security. By design. Active } \\
\text { (CCTV/security personnel); visual/open; All buildings to meet a "Green Star" rating (for tropics): } \\
\text { materials, energy efficiency, air quality; Use of natural products for building materials where } \\
\text { possible. I.e. Plantation timber, natural fibre carpet. } \\
\text { The built environment: all buildings etc. to be sympathetic to tropical environmental conditions; } \\
\text { embodied energy considerations in material use and recycle. Safety considerations; Maintain } \\
\text { natural landscapes (flora and fauna) and vegetation (grass, woodlands) with water sensitive urban } \\
\text { design and landscaping; Maintain and promote open spaces with surroundings. Open spaces } \\
\text { within the residential and throughout the uni "provide a park at the end of every street". } \\
\text { Shade and ventilation; developmental covenants to enforce height, spatial, materials; creative } \\
\text { distributions of positive and negative spatial relationships; community gardens/composting; } \\
\text { Contractual arrangements for building construction - tangible and intangible. Internal university } \\
\text { strategy for space management; Low energy, climate responsive, low carbon footprint, suited to } \\
\text { tropics. Buildings which maintain open space through non aversion to height. (open high rise); } \\
\text { Building design: lighting not reflecting to night sky; reduce carbon footprint; climate responsive } \\
\text { design. }\end{array}$ \\
\hline
\end{tabular}




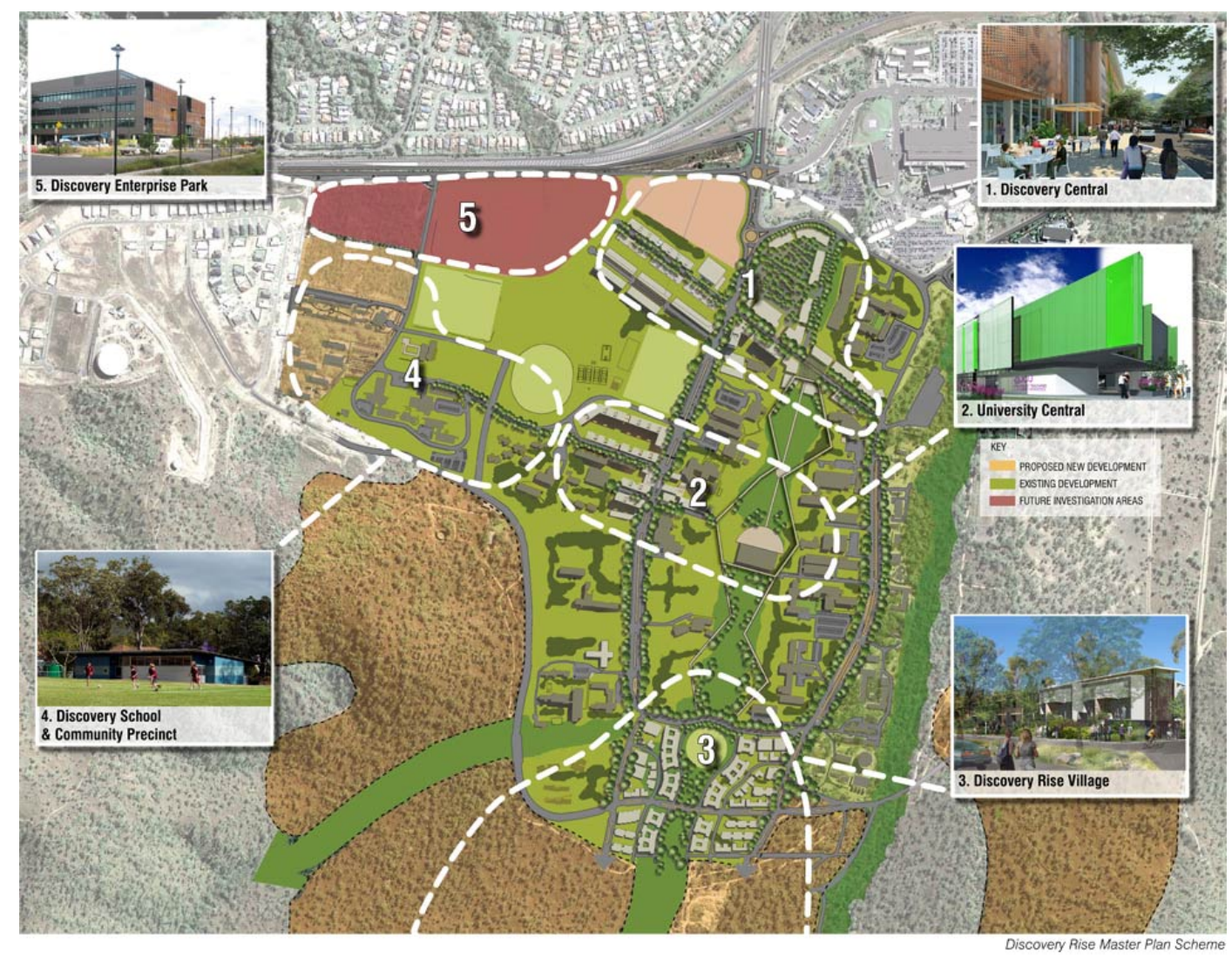

Source: http://www.discoveryrise.com.au/planning

Figure 6. The intent of the university in 2013 for Discovery Rise

\section{SIP Law and Policy}

\subsection{Our Politically Preferred Future is Clear}

Through a lengthy consultation and inclusion process, the federal government introduced AMCORD (AMCORD 95) in 1995 - The Australian Model Code of Residential Development - the first federal effort at national urban planning guidelines which the states, territories and local governments were required to adapt and adopt. This led to laws and policies in all Australian jurisdictions, like the Sustainability Planning Act (2009) in Queensland.

The "Purpose of Act [Part 2.3] is to seek to achieve ecological sustainability by- ensuring the process ... delivers sustainable outcomes. [Part 5 .. and will..]: take account of short and long-term environmental effects of development at local, regional, State and wider levels, including, for example, the effects of development on climate change, and (iii) apply the precautionary principle. and (iv) seek to provide for equity between present and future generations; and ensuring the sustainable use of renewable natural resources and the prudent use of non-renewable natural resources by, for example, considering alternatives to the use of non-renewable natural resources, and (c) avoiding, if practicable, or otherwise lessening, adverse environmental effects of development, including, for example- (i) climate change and urban congestion; and (ii) adverse effects on human health; and (d) considering housing choice and diversity, and economic diversity; and (e) supplying infrastructure in a coordinated, efficient and orderly way, including encouraging urban development in areas where adequate infrastructure exists or can be provided efficiently; and (f) applying standards of amenity, conservation, energy, health and safety in the built environment that are cost-effective and for the public benefit; and $(\mathrm{g})$ providing opportunities for community involvement in decision making." (QG 2009).

\section{Discussion - Leverage in Quantifying Sustainability}

There are local government policies reflecting the same values and principles as the above-quoted state government urban planning law, requiring greater pedestrianisation, more paths and more 'efficient' landuse (TTSP 2000). The workshop participants overwhelmingly supported these ESD goals, and offered practical criteria to help usher them in.

Planners, residents and all entities have some inherent 'stake' in our collective future, but the pivotal challenge to get from the above planning intent to implementation will flow more from addressing the unmet demand displayed by workshop participants than from clinging to an old way of doing planning business. That 'old way' ignores embodied and operating energy and water calculations over the life of an intended project. The accounting is incomplete. 
The workshop outcomes summarised above are a rich mine to guide SIP and evolving urban access/travel, landuse and home location choices. A focus on access to and through activity centres is one necessary prism through which to conceptualise and plan SIP, as part of a WEMFACS set of SIP checklists of concurrent and interlocking sustainability planning issues (Figure 4), where WEMFACS $=$ Sustainable Water, Energy /environment /economics/ engineering/ education, Management, Food, Access/ amenity, Culture/cohesion/commercial and Social dynamics.

Bruntland (1987) recorded the global sustainability intent and principles. Human geographers have a well-developed debate on sustainable development, un-linking development issues and just speaking of sustainability (Sneddon 2002). Sneddon argues for thematic socio-ecological transformation, along with authors like Arvidsson (2009) delving into ethics and current values, Bassett (1999) writing on the sociology of science and Bdour et al (2009) considering sustainable wastewater treatment and reuse. Bergen et al (2001) define design principles for ecological engineering; Campbell and Laherrere (1998) 'mainstreamed' the concept of peak oil and Capps (2009) outlined Green buildings. The City of Melbourne (2008) provides one of the few built examples where the VP\&P approach has been comprehensively applied to 'Council House 2' in Melbourne. Akin and Wehbe (2009) considered vulnerability with system sustainability.

Geographers compare economics in sustainability with the 'old' linear industrial model (get, use, throw away), providing a more 'organic 'neoclassical circular flow model (Sneddon 2002). The emergent literature and the input from the DR Paths to sustainability workshop converge on needing to measure the total set of issues included in Sustainability Implementation Science (SIS). Figure 4 provides a visualisation of the issues in the SIS equation:

Urban Sustainability Quotient $=\mathrm{f}$ (PxEuxWxExEcxAxSc $\mathrm{xM})$. Equation 1, linked to Figure 4.

Thus an intended project can gain a sustainability quotient by defining it as a function of Place (P) in the micro, macro and climatic detail, as place relates to End users $(\mathrm{Eu})$ and intended functions, by asking end-user representatives exhaustively and iteratively what they need and want. This is functionally related to needs-meeting for Water (W), both embodied and operational water use, considering local water capture, re-use, nutrients and food production. Needs-provision includes Energy (E), quantified by comparing embodied (materials and construction)and operating energy choices, aiming for projects to be fossil carbon neutral, to have maximised on-site renewable generation and storage, with maximised passive building/landscape designs.

Economic success (Ec) is core to 'place' success. Access (A) is strictly an energy issue, but from a needs-meeting perspective, people, goods, materials and information need to get access to and through all scales of activity centres. People access (car or alternatives-based) is important to health, vibrancy and a low carbon footprint. Also, successful and sustainable people places need to have Social/Cultural
(Sc) diversity and vibrancy. Without that, 'place' will tend not to attract people.

\subsection{Curve 1}

'Curve One' of Figure 2 could be labelled 'The breakout or upstart species', or 'One-shot planet faces macro-threat'. If our current global population were to live at Vancouver's ecological impact level, we would need 3 planets like earth to meet our current needs (Moore et al 2013). In time and space, Curve 1, currently near exponential, cannot continue its trajectory. This is where our astounding capacity for thought, planning and cooperative social behaviour need to somehow assert and win over passively resistant group and various decision-making hierarchies indicated in Figure 1.

Much of our collective future is to do with group psychology, power, and our capacity to place long-term wellbeing as the premier screen and filter through which we see ourselves and the biota remnants in time and space. For science to write of the need for wisdom only reflects that science is the effort to testably describe and explain changing reality. Wisdom exists, the evidence of Curve one exists, and is the basis for arguing that variants of business-as-usual are unsustainable. The VP\&P approach to planning advocated in this and most current planning literature acknowledge that it can be science to say we care, including our care about the broadest long term best interest of our urbanising species of unparalleled collective prowess.

\subsection{The Future}

Integrating land use and urban travel into one conceptual frame of people living and moving about the urban landscape with minimum daily and weekly travel is the 'new' shift in urban planning, from reductionist to holistic planning for people. This translates as higher density urban nodes where most needs are met within that node. Calculations of embodied and operating water and energy use in the built environment; integrating housing with usual destinations is a core part of urban sustainability, SIP. This holistic settlement will have safe, continuous, smooth, direct and broad paths to and through all scales of urban nodes, central to SIP.

Finally, workshop participants were emphatic that Management linked all the other parameters; management and ongoing control of the process, from initial conception to long-term function; innovation, conservatism and adaptation are necessary to sustainability success. As external and internal realities change, so inclusive management must anticipate and administer anything from benign dictatorship to fully end-user directed management, with key structures to ensure the agreed VP\&P are the decision filters to a long-term dynamic balance with the remnants of nature.

Like Social Indicators, much of the science of human impact is well evolved, e.g.www.footprintnetwork.org.Soci al Indicator measures (i.e. Schwirian 1995, Royuela et al 2009), quantify the quality of life. This quantification of social indicators of well-being is a mature field in social 
science. There are often 20 factors used to quantify quality of life.

Royuelaetal (2009) quantified commuting from different parts of Catalonia. They found local travel wellbeing was dependent on access to shopping, work and study, leisure activities and health care commute attributes. Royuela et al assert the research-backed value that "the main aim of spatial planning is to make direct improvements on the quality of life" (p 438, 2009).

\subsection{Measuring and Comparing Environmental, Energy, Economic and Social Sustainability}

Relevant to the core themes of this paper, Amekudzi et al (2009) develop a sustainability footprint framework and model. Aligned with developments leading the DR aspirations, Amekudzi considers the ecological and the social issues - the measurable quality of life issues (Schwirian 1995) in relation to environmental impacts, the beginnings of consensus on measuring sustainability (Figure $4 \&$ Equation 1). Put simply, "countries or other entities that have experienced little or no change (or a decrease) in their quality of life with a simultaneous increase in the ecological footprint per capita can be considered to be moving away from sustainability." (Amekudzi et al 2009, p343).

No planning discussion is complete without placing peak oil and local food provision - the elephants in the car-based landscape - prominently when imagining our urban spaces; our nodes or activity centres and their links 20 years from now (Figures 6 and 7).

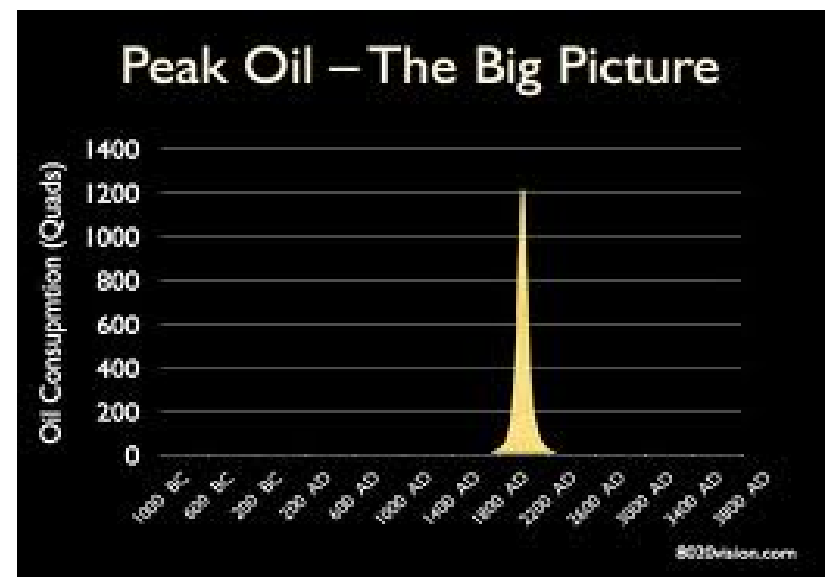

https://www.google.com.au/search?q=peak+oil\&tbm=isch\&tbo=u\&source $=$ univ\&sa $=$ X\&ei $=\mathrm{ieVdUrXRIoybiQeLhIGgAw \& sqi}=2 \&$ ved $=0$ CEsQsAQ $\&$ biw $=1280 \&$ bih $=905 \& \mathrm{dpr}=1$

Figure 7. Peak oil

\section{SIP Urban Travel Process Detail}

Given the focus of this paper on sustainable urban access; knowing that housing choices as they relate to usual householder daily and weekly destinations and links with broader nodes, workshop participants and the current literature underline that sustainable urban access needs to:
1. Continue engaging institutional and bureaucratic decision-makers in the urgency of SIP.

2. Integrate all government and place-based approaches to planning; include urban transport planning groups with urban land use/land release groups, to integrate the land use/urban travel approach to planning: 'Landuse and consequent urban travel detail' are one issue. This is where an overarching awareness of Figure 1 is needed.

3. Work with decision-making groups and end-users at the destination/Activity Centre level to articulate and help design safe, continuous, smooth, direct and broad paths to and through every Activity Centre.

4. Work with landowner administrators to ensure that end of trip facilities (secure covered bike storage and showers for riders) are available for all path users.

5. Ensure that any new or upgraded major road or centre includes cohesive path access and passage.

6. Within the values of SIP, ensure that there is an ongoing dialogue between existing and potential end-user cyclists, wheelchair and pram users and pedestrians to explore and map preferred access (desire lines) to and through activity centres.

7. Integrate sustainable urban travel, including attractive public transport with all other aspects of urban sustainability in ways described in this paper.

\section{Conclusion}

This paper shows how to embrace sustainability values, and articulate the flow-on SIP principles and processes. With the ability to create comparative impact and outcome data there will be empirical guidance that reductionist specialists, planning administrators and decision-makers can use to fully usher in urban sustainability. There is an emergent intellectual framework, combining all the attributes of reductionist science with shared human values. This combination of carbon footprint calculations with water use and 'environmental and ecological footprints' and social indicators to form the new Sustainability Implementation Science. JCU is pioneering this intent into practice in Townsville, north Queensland Australia.

Sustainability laws and intent are ubiquitous, through impressive words and diagrams, but the passage from sustainability intent to sustainability delivery is fraught with institutional and bureaucratic barriers. The clearly stated and detailed needs of more sustainable urban travel from the Paths to Sustainability workshop are increasingly articulated in the literature. If top-level lawmakers, managers and decision-makers are prepared to lead their organisation's policy into practice, there is a need to envisage sustainable futures, and then quantify the long-term impacts of various choices.

The great disappointment for this long-time advocate, researcher, consultant and lecturer of sustainability implementation is that it seems planning practitioners largely keep choosing a 'middle path'. Workshop 
participants were adamant that sustainability implementation needed a whole-of-system approach. The ongoing gap between what is needed for sustainability and what is happening with the implementation is like saying that pregnancy is desirable, but shying away from the commitment into the unknown. You cannot be a 'bit' pregnant. Administrators' overarching institutions seem as bedeviled by the disjunction between desire and implementation as the broader political players 'get' global warming and the need to drastically reduce fossil fuel use and the great and easy attraction of continuing that use. As the species of great prowess, we are selectively blind to the physical evidence of a finite planet and the impossibility of 'Curve 1' going up exponentially into even the midterm future. There are urban food gardens in some cities, there is increased bicycle use across the 'developed' world, but our great appetite for consumables will continue. Engagement between 'knowledge holders' and 'decision-makers' never seemed more important for avoiding what happened, in effect, to so many cultures where consumption outstripped supply. We are the species of great prowess, 'going global' for the first time, on this 'one shot' planet.

Political structures, in the extreme, like the Taliban or, as sadly, the Tea Party (of the USA) are divorced from the changing and testable consensus reality that is science. Equally, many decision-makers are torn between variants of business as usual, perhaps safely keeping their jobs; or stepping bravely into a future which is not yet knowable. By clarifying values, articulating principles which define a process to get from 'now' to a long-term viable future, the contents of this paper may help decision-makers resolve in heading for the planning choices which are most likely to remain appreciated hundreds of years from now.

What is at issue is the will of decision-makers to accept the contents of papers like this and move, as increasing numbers are doing, to take more responsibility for the future, to do more than just make token paths and pretty parks. To do more than pluck some high visibility 'low hanging fruit'. There are increasing examples worldwide that such transformations are happening. The only limit is the time to embrace and prepare for a low-impact human future of technology and largely local need-meeting. If one group of participants in Townsville, north Queensland Australia can define so much detail of what is sustainable in just one day, no-one can plead that we didn't know what to do. The information is there.

Taking policy into practice, the rationale, will, legal requirements and emergent tools exist to embrace and implement sustainable urban planning without further delay. If issues at the relatively micro level (JCU Townsville) are fractals of the macro-level issues of climate change, population increase, depleting petroleum reserves and an effective Emissions Trading Scheme, it is the VP\&P approach that may usher in the needed new way of planning, where the long-term is central to decision-making. Institutions, rather than protecting their old 'closed' power structures and relationships need to reach out in meaningful networks considering place, purpose and human needs-meeting.
Like increasingly marginalised 'climate skeptics', there are decision-making 'sustainability skeptics' who block initiatives as unnecessary, untried or unknown; and thus intimidating. Scenario quantification takes the environmental footprint with social measures of well-being to produce a sustainability index. This provides the capacity to compare alternative planning choices over the life of the project, including prior 'externalities' like embodied and operational energy and water use. The workshop emphasised the need for clear and effective links between JCU and the broader community and for Discovery Rise to become a central transport node, with weather-protected paths and possibly high-rise housing, with high parking fees and safety as part of the push-pull strategies to have more paths and less cars into the future. Mixed and blended land use was advocated, along with social and cultural diversity.

Using guidelines provided by the workshop and current literature, quantifying urban sustainability choices, outlined in this paper will become the lever to strongly and rapidly usher in SIP. The oversubscribed workshop and impressive level of offers for ongoing input shows a strong unmet demand and will for SIP in North Queensland. The current literature indicates the will and desire is widespread, as 'carbon footprint', 'peak oil' and 'climate change' enter our mainstream language and understanding. Changing our energy, water and food procurement and use to the local scale are major but achievable challenges for sustainability planners. Because of our growing understanding of peak oil, commitment to SIS and its analysis tools can be applied to landuse/urban travel planning to change from car-based to public transport and path-based urban travel. This stands as a pressing and permanent change we need to make in reconfiguring the urban landscape to sustainable urban futures.

\section{REFERENCES}

[1] Amekudzi AA, Khisty CJ, Khayesi M 2009. Using the sustainability footprint model to assess development impacts of transportation systems. Transportation Research Part A 43 (2009). $339-348$

[2] Arvidsson A 2009. The ethical economy: Towards a post-capitalist theory of value. Capital \& Class; $97.13-29$.

[3] Barnes TJ 2004. The Progress in Human Geography lecture Placing ideas: genius loci, heterotopia and geography's quantitative revolution. Progress in Human Geography 28, 5 (2004) pp. 565-595.

[4] Banister D 1996. Energy, quality of life and the environment: the role of transport. Transport reviews 16:1. 23 - 35 .

[5] Bassett K 1999. Is there progress in human geography? The problem of progress in the light of recent work in the philosophy and sociology of science. Progress in Human Geography 23, 1 (1999) pp. 27- 47.

[6] Bdour AN, Hamdi MR and Tarawneh Z 2009. Perspectives on sustainable wastewater treatment technologies and reuse 
options in the urban areas of the Mediterranean region. Desalination. 237:1-3. Pp162 -174.

[7] Bergen SD, Bolton SM and Fridley JL 2001. Design principles for ecological engineering. Ecological Engineering 18(2001). 201-210.

[8] Bruntland G (Ed) 1987. Our Common Future. World Commission on Environment and Development. Oxford England. Oxford University Press.

[9] Campbell CJ and Laherrere JH 1998. The end of cheap oil. Sci. Am. 3:278, 60-65.

[10] Capps K 2009. Green building blues. The American Prospect. $20: 2.35-37$

[11] City of Melbourne 2008. Council House 2. http://www.melbourne.vic.gov.au/info.cfm?top=171\&pg=19 33

[12] Eakin HC and Wehbe MB 2009. Linking local vulnerability to system sustainability in a resilience framework: two cases from Latin America. Climatic Change. 93:3-4. 355 - 378.

[13] Ghosh S, Vale R and Vale B 2009. Local food production in home gardens: measuring on-site sustainability potential of residential development. International Journal of Environment and Sustainable Development. 7:4. 430-451.

[14] Goudie D 2001. Toward Sustainable Urban Travel. PhD thesis. James Cook University. http://eprints.jcu.edu.au/967/

[15] Goudie D 2002. Zonal method for urban travel surveys: sustainability and sample distance from the CBD. Journal of Transport Geography 10: 287 - 301. Elsiever. http://www.sciencedirect.com/science?_ob=ArticleURL\&_u 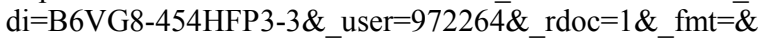 orig $=$ search\&_sort $=\mathrm{d} \& \overline{\mathrm{i}} \mathrm{ew}=\mathrm{c} \& \_$acct $=\overline{\mathrm{C} 000049659} \&$ \&vers ion $=1 \&$ urlVersion $=0 \&$ userid $=972264 \& \mathrm{md} 5=2508 \mathrm{c} 380 \mathrm{c} 0$ d8bbe $8 \bar{b} 66$ a225d5969a $9 \overline{3} \mathrm{~d}$

[16] Goudie D 2013. Natural Disasters and evacuations as a Communication and Social Phenomenon. In: Meyers R. (Ed.) Encyclopedia of Complexity and Systems Science: SpringerReference (www.springerreference.com) Springer-Verlag Berlin Heidelberg, 2013. Doi: 10. 1007/SpringerReference_60358 2013-06-18:18:31 UTC $\mathrm{http} / / / \mathrm{www}$. springerreference.com/docs/html/chapterdbid/60 358.html

[17] Harris E 2009. The role of community gardens in creating healthy communities. Australian Planner, 46:2. 24-27.

[18] JCU 2008. University Plan.
[19] JCU 2013. http://www.discoveryrise.com.au/about/the-vision

[20] Koo DH and Ariaratnam ST 2008. Application of a Sustainability Model for Assessing Water Main Replacement Options. Journal of Construction Engineering and Management. 134:8. 563 - 574.

[21] Moore J, Kissinger M, Rees W 2013. An urban metabolism and ecological footprint assessment of Metro Vancouver. Journal of Environmental Management V24, P51-61.http://br9xy4lf5w.search.serialssolutions.com/?ctx_v er $=Z 39.88-2004 \&$ ctx enc $=$ info $\% 3$ Aofi $\% 2 F e n c \% 3$ AUTF- 8 \&rfr id=info:sid/summon.serialssolutions.com\&rft val fmt =info:ofi/fmt:kev:mtx:journal\&rft.genre $=$ article\&rft.atitle $=A$ $\mathrm{n}+$ urban + metabolism+and+ecological+footprint+assessment + of + Metro+Vancouver\&rft.jtitle $=$ Journal + of + environmental + management\&rft.au $=$ Moore $\% 2 \mathrm{C}+$ Jennie $\& \mathrm{rtt} . \mathrm{au}=\mathrm{Kissinger}$ $\% 2 \mathrm{C}+$ Meidad\&rft.au $=$ Rees $\% 2 \mathrm{C}+$ William + E\&rft.date $=2013$ -07-30\&rft.eissn $=1095-8630 \&$ rft.volume $=124 \&$ rft.spage $=51$ \&rft_id=info:pmid/23603775\&rft.externalDocID=23603775 \&paramdict=en-US

[22] Queensland Government 2009. Sustainable Planning Act. http://www.dsdip.qld.gov.au/planning-and-development/sust ainable-planning-act-2009.html

[23] Royuela V, Roman J and Art1 M 2009. Using Quality of Life Criteria to Define Urban Areas in Catalonia. Soc Indic Res. 90:419-440.

[24] Schwirian KP, Nelson AL and Schwirian PM 1995. Modeling urbanism: economic, social and environmental stress in cities. Social indicators research. 35:2, 201-223.

[25] Sneddon C 2000. 'Sustainability' in ecological economics, ecology and livelihoods: a review. Progress in Human Geography. 24:4. $521-549$.

[26] TTSP 2000. Townsville/Thuringowa Strategy Plan. Framework for managing growth and development. Queensland Government, Department of Communication and information, local government and sport. 62 .

[27] Turner BL and Robbins P 2008. Land-Change Science and Political Ecology: Similarities, Differences, and Implications for Sustainability Science. Annual Review of Environment and Resources. 33:1. $295-316$.

[28] Yakubov M 2009. Water for food as food for thought: case study of applying the PODIUMSim model to Uzbekistan. Irrigation and Drainage. 58:1. 17-37.

[29] Walmsley DJ and Lewis GJ 1993. People and the environment. Behavioural approaches in human geography. 2nd Ed. Longman. 